\title{
The Enhancement of the International Influence of TCM Cultural Soft Power Under the Belt and Road Initiative
}

\author{
Fangmeng $\mathrm{Li}^{1}$, Dejun $\mathrm{Li}^{1, *}$ and Xueli Ding ${ }^{1}$ \\ ${ }^{1}$ School of Foreign Languages, Hubei University of Chinese Medicine, Wuhan, Hubei 430065, China \\ *Corresponding author. Email: jasonldj@qq.com
}

\begin{abstract}
With the continuous development of the Belt and Road Initiative, the pace of Chinese culture's international exchange has been significantly accelerated, and China's cultural soft power has also been greatly enhanced. Under such circumstances, TCM culture, as an important part of China's cultural soft power, has ushered in unprecedented opportunities for its international communication. This article is going to discuss the significance of enhancing the international influence of TCM cultural soft power under the Belt and Road Initiative, and then combines with the difficulties and challenges faced by the international communication of TCM culture to further explore the effective measures of enhancing the international influence of TCM cultural soft power.

Keywords: TCM Cultural Soft Power, International Influence, Belt and Road Initiative
\end{abstract}

\section{INTRODUCTION}

The Belt and Road Initiative is a major strategic deployment launched by the Chinese government based on the comprehensive assessment of both domestic and international situations. The Belt and Road Initiative is not only a proposition of economic cooperation but also a platform for foreign cultural exchange. Therefore, the development of the Belt and Road Initiative will further promote the international communication of Chinese culture and enhance the international influence of Chinese cultural soft power. Traditional Chinese medicine culture (TCM culture for short) is an important part of the excellent traditional culture of China, which embodies the cognitive style, value orientation and aesthetic taste of China and is also an important component of China's cultural soft power.[1] Since the beginning of China's Reform and Opening-up, especially in the past 10 years, the international exchange of TCM has become increasingly frequent, and the culture of TCM has gradually gained recognition and respect throughout the world, and has played a more and more important role in the construction of China's cultural soft power. Specifically, TCM cultural soft power mainly refers to "the national cohesion, independent innovation and cultural communication power contained in the longstanding TCM civilization, and the profound influence exerted on other people or other nationalities."'[2] The promotion of TCM cultural soft power and the enhancement of its international influence will not only further push forward the development of world medicine, but also help us better promote Chinese culture abroad and enhance the appeal and attraction of Chinese culture in the world, thus elevating the overall strength of Chinese cultural soft power.

\section{THE SIGNIFICANCE OF ENHANCING THE INTERNATIONAL INFLUENCE OF TCM CULTURAL SOFT POWER}

As an important component of China's cultural soft power, it is of great significance to enhance the international influence of TCM cultural soft power under the framework of the Belt and Road Initiative to better serve China's foreign strategy, which will not only benefit the construction of "Closer People-to-People Ties" project of the Belt and Road Initiative to comprehensively promote the cultural exchanges between China and countries along the Belt and Road, but also facilitate the building of the Silk Road of Health to further speed up the integration of TCM into the international medical system to make TCM better serve the health and well-being of the people of countries along the Belt and Road.

\subsection{Benefiting the Construction of "Closer People-to-People Ties" Project of the Belt and Road Initiative}

The Belt and Road Initiative is more than just a simple concept of space and geography or economic and trade cooperation. It is a giant systematic project with five key construction areas, namely Five-Pronged Approaches, which includes Policy Coordination, Connectivity of Infrastructure, Unimpeded Trade, Financial Integration and Closer People-to-People Ties, and its primary goal is to jointly build a community of shared future with mutual political trust, economic integration, and cultural tolerance. 
Within the Five-Pronged Approaches, the "Closer Peopleto-People Ties" project is the root of the smooth development of the Belt and Road Initiative. Focusing on cultural exchanges, it is committed to promoting the cultural identification among the people of countries along the Belt and Road and strengthening the mutual public support basis for exchanges and cooperation in all the fields.

As an outstanding representative of traditional Chinese culture, TCM culture contains unique health concepts and universal medical humanistic spirit, which makes it easier to narrow the distance between Chinese culture and the people of countries along the Belt and Road, reduce their prejudice to Chinese culture and enhance their recognition of Chinese culture. In reality, since the implementation of the Belt and Road initiative, the number of foreign students studying TCM in China keeps growing. It is estimated that every year there will be more than 13,000 foreign students coming to China to study TCM. In addition, hundreds of TCM colleges and universities have been established in more than 30 countries and regions, more than 10 TCM Confucius Institutes have been set up on all continents, and 17 TCM centres have been built overseas.[3] All of these have greatly contributed to the increasing recognition of Chinese culture by the people of countries along the Belt and Road. Therefore, with the continuous promotion of TCM in countries along the Belt and Road, Chinese culture represented by TCM culture is being recognized by more and more foreign people, and the soft power of TCM culture is constantly enhancing the spiritual connection between the people of countries along the Belt and Road and the Chinese people with its strong attraction and influence, thereby effectively boosting the construction of the "Closer Peopleto-People Ties" project of the Belt and Road Initiative.

\subsection{Facilitating the Building of the Silk Road of Health under the Framework of the Belt and Road Initiative}

Health is a common topic for all mankind, a fundamental condition for the social and economic development of a country and region, and the primary symbol of national prosperity. With the change of society and environment, the acceleration of people's pace of life, the aging of population and the change of disease spectrum, human health is faced with more and more new problems and challenges, which makes medicine in the 21 st century begin to gradually change from "disease-treating medicine" to "healthpreserving medicine". As an important ideological and methodological system for the Chinese nation to understand life, maintain health, and prevent diseases for thousands of years, TCM has been the primary means for Chinese people to treat and prevent diseases, maintain health, and prolong life since ancient times. It can be said that although the Chinese nation has experienced all kinds of major disasters, it can still live and pass on from generation to generation, in which TCM has made great contributions.

To jointly build the Silk Road of Health, promote medical and health cooperation among countries along the Belt and
Road and safeguard human health and well-being is one of the important contents of the Belt and Road construction, among which TCM will undoubtedly play an important role. The continuous increase in the influence of TCM cultural soft power in the countries along the Belt and Road will further enhance the scientific understanding of the medical attributes of TCM among the local people of these countries, and make them develop a sense of identity to the diagnosis and treatment of TCM and ultimately willing to use TCM to prevent or treat diseases, thus letting TCM play a greater role in the building of the Silk Road of Health. In reality, since the COVID-19 pandemic began to ravage the world at the beginning of 2020, the unique advantages of TCM in the prevention and treatment of COVID-19 have attracted great attention from many countries in the world, including countries along the Belt and Road. Medical experts and teams in some countries have organized professional antiepidemic teams to strengthen medical technical cooperation with China and learn from China's anti-epidemic experiences. According to the statistics, the first seven editions of Diagnosis and Treatment Protocol for Novel Coronavirus Pneumonia and the first six Prevention and Control Protocol for Novel Coronavirus Pneumonia released by Chinese government have been translated into multiple languages and shared with more than 100 countries and more than 10 international and regional organizations.[4] In the above-mentioned protocols, diagnosis and treatment methods and prevention measures related to TCM are undoubtedly a highlight, which can effectively enhance the influence of TCM cultural soft power in the countries along the Belt and Road, and enable TCM to be better integrated into the daily medical activities of these countries. These practices are of great significance to jointly build the Silk Road of Health and open a new cooperation space for the Belt and Road.

\section{DIFFICULTIES AND CHALLENGES FACED BY THE INTERNATIONAL COMMUNICATION OF TCM CULTURE}

Since the implementation of the Belt and Road Initiative, unprecedented achievements have been made in the international communication of TCM. For example, according to the official statistics in 2016, the Chinese government has signed 86 TCM cooperation agreements with relevant countries and international organizations and set up 10 TCM centres overseas. Chinese acupuncture and moxibustion have been inscribed on the Masterpiece of the Intangible Cultural Heritage of Humanity by UNESCO and The Yellow Emperor's Classic of Internal Medicine and Compendium of Materia Medica have been inscribed on the Memory of the World Register.[5] Although the international communication of TCM culture has made huge achievements, there still exist some difficulties and challenges. 


\subsection{The Immense Cultural Barriers Between China and the West}

Since huge gap exists in history, culture, geography, politics, economy and so on, there are diversities in the understanding of medicine between China and the West. TCM originally developed with the emergence of agricultural civilization in ancient China and is based on the theory of Yin and Yang. It emphasizes the holistic view and advocates the "unity of man and nature". Its treatment is based on syndrome differentiation, which is quite different from western medicine that is based on anatomy and physiology and derived by modern scientific development. With the global expansion of western politics, economy, and culture, western medicine has spread to the whole world, and its medical knowledge and ethics have won the general recognition of the whole world. Such global common understandings make it much hard for TCM to achieve the trust of people from other countries, because they are unwilling to learn and accept TCM culture which is not only totally different from western medicine, but also too extensive and profound to understand. In addition, for political, economic, and ideological reasons, some countries restrict the use of TCM by their citizens and resist the exchange of TCM culture. All these have caused the deepening of the cultural gaps between Chinese and Western medicine and hindered the international communication of TCM culture.

\subsection{The Inadequate Standardization of TCM}

The construction of standardization is an important part for TCM's scientific development and going to the world, however, the level of standardization of TCM is relatively low no matter from the state standards or industrial standards, including less than 300 national standards, accounting for only $0.65 \%$ of the national standards, and less than 500 industrial standards, accounting for only $0.69 \%$ of the industrial standards. The standardization of TCM has not yet covered all fields of TCM.[6] In the current international environment where western medicine prevaricates, the situation of low standardization will undoubtedly greatly weaken the international voice of TCM, make TCM have no advantage in international competition, and also lead foreign people to obtain a skeptical attitude towards TCM, which will inevitably hinder the spread of TCM culture in the local area. In addition, TCM terms are mostly derived from ancient historical classics, which are far from modern Chinese. Therefore, it has to be firstly translated from ancient Chinese to modern Chinese and then to foreign languages. This makes it extremely difficult to understand TCM terms in translation, resulting in a variety of translated versions with no consensus can be reached. Such nonstandard translation terms often make foreign people confused and hinder them from forming a scientific and accurate cognition of TCM and ultimately hamper the recognition and acceptance of $\mathrm{TCM}$ culture in foreign countries.

\subsection{The Insufficient Network Construction of the International Communication of TCM Culture}

The international communication of TCM culture has mainly relied on two major channels for a long time: one is to carry out the external communication of TCM culture with experts, scholars and practitioners as the main body, while the other is to promote and publicize TCM culture under the guidance of the government. There is no doubt that both of these two means play an important role in the foreign communication of culture. However, most of their knowledge are too professional to achieve a mass communication overseas, let alone effectively narrow the gap between the normal folks and TCM culture. At present, the rapid development of computer networks and information technology has ushered in a new era of mass media. The Internet, with its advantages of convenience, efficiency, and wide coverage, has brought new opportunities for us to spread TCM culture more comprehensively to the outside world. Chinese government has also started to pay attention to the role that Internet and new media technology played in the spread of TCM culture and issued a series of policies to guide the popularization of TCM culture, relevant government departments and both enterprises and institutions are committed to the network construction of TCM culture, and have obtained some achievements, but from a practical perspective, the network construction of TCM culture is still in a primary stage, its contents, forms, and channels of related network communication are still too simple and single as well as the development of digital cultural products still needs to be further strengthened. Undoubtedly, all these problems greatly restrict the promotion of the international influence of the soft power of TCM culture in the information age.

\subsection{The Shortage of Professional Translators for the International Communication of TCM Culture}

To enhance the soft power of TCM culture and its international influence, what we need first is to build a team of adequate compound talents for international communication of TCM culture with multi-disciplinary knowledge such as TCM, translation and communication. However, in the current domestic education system, there are few compound TCM professionals with excellent translation and international communication ability and there is also a serious shortage of foreign language talents who can independently fulfill the task of the translation and international communication of TCM, which has become one of the most fundamental hardships restricting the international communication of TCM culture. In recent 
years, although there are many colleges and universities having started to offer English courses of TCM and set up TCM English major, recruit masters of translation in the direction of Chinese medicine, there is still a big gap between the talents cultivated and the talents actually needed at present due to insufficient school running experience and the shortage of teachers. Especially under the background of the Belt and Road, the contradiction between the supply and demand of talents for international communication of TCM culture is more prominent in the face of different languages and cultures.

\section{STRATEGIES TO ENHANCE THE INTERNATIONAL INFLUENCE OF TCM CULTURAL SOFT POWER}

The in-depth advancement of the Belt and Road Initiative has brought unprecedented development opportunities for the international communication of TCM culture. In order to better promote TCM culture in the countries along the Belt and Road and enhance the international influence of TCM cultural soft power, we now need to actively change our ideas, improve communication strategies and elevate the level of communication, so as to continuously expand the international identity of TCM culture, enhance the influence of TCM culture in the countries along the Belt and Road and eventually make TCM better serve the well-being of all the people in the countries along the Belt and Road, which is particularly important in the next few years when COVID19 might still rage around the world. To achieve this goal, we need to focus on the following points in the future.

\subsection{Adhering to the Cultural Globalization Development Concept of "Seeking Common Ground while Reserving Differences"}

Cultural globalization is the general trend of development in today's international community. If China's cultural soft power needs to continuously expand its international influence in the wave of globalization, it must adhere to the cultural inheritance and development concept of "seeking common ground while reserving differences". The same is true for the international dissemination of traditional Chinese medicine culture. Only in this way can we break the cultural barriers between China and foreign countries, and allow TCM culture to continuously expand its international influence in the integration and development with the culture of other countries. Specifically, it is sensible to start from the perspective of cultural adaptation, aim at the different historical and cultural backgrounds and political and economic systems of the countries along the Belt and Road, as well as the different acceptance levels of TCM culture, and adopt the personalized communication strategy with the adherence to the principle of "seeking common ground while reserving differences" to allow TCM culture to actively adapt to the different needs of countries along the Belt and Road, instead of blindly exporting it all. For example, the population aging problem has been very serious in countries like Malaysia, Singapore, Thailand, Indonesia, and Vietnam. Therefore, the spread of TCM culture in these countries can focus more on TCM products for the treatment of chronic diseases of the elderly to constantly meet the urgent health needs of the people in Southeast Asia and gradually increase the contribution of TCM health services to these countries to accordingly better promote the spread of TCM culture in the local area.

\subsection{Cultivating Qualified TCM Translators and Accelerating the Standardization of TCM Translation}

The standardization of TCM is an important part in the sustainable development of TCM. On the one hand, it is of great necessity to continue promoting the construction of national and industrial standards for TCM to meet the standardization demand of every field in TCM; on the other hand, In the process of TCM the internationalization, Great importance must be attached to the promotion of the standardization of TCM translation, which mainly includes to standardize the translation of TCM terminology and classics, to completely change the situation where various versions of TCM translation are everywhere on the market, resulting in overseas readers often getting lost when reading such translated works. Only in this way can foreigners understand TCM more accurately and scientifically. In the process of the standardization of TCM translation, the key is to cultivate a group of "TCM + foreign language" compound talents, in which the national TCM colleges and universities undoubtedly play an important role. On the one hand, TCM colleges and universities can set up some special classes with the characteristics of foreign language learning in TCM majors. In these classes, in addition to learning professional TCM knowledge and skills, students need also strengthen their abilities in foreign language proficiency and TCM translation. On the other hand, the qualified TCM colleges and universities can offer undergraduate majors in foreign languages and master's programs in translation with TCM characteristics, so that students can learn the basic theoretical knowledge of TCM systematically while learning foreign languages and translation. Such a twopronged approach will surely cultivate a group of outstanding foreign-oriented talents in TCM and translation as soon as possible.

\subsection{Expanding the International Communication Channels of TCM Culture by Relying on the Internet New Media Technology}

The rapid development of new media technologies on the Internet and the advent of the era of $5 \mathrm{G}$ and artificial intelligence have provided more possibilities for the efficient communication of information, which has also created a new way for the international communication of TCM culture. In the information age, if TCM culture is to be 
popularized conveniently and efficiently in the countries along the Belt and Road, we must give full play to the role of new media technologies and create a "Internet + TCM" online communication platform. On the one hand, high-level Internet technical teams must be first established to set up systematic online platforms for the international communication of TCM culture, and at the same time build high-calibre talent teams with TCM background and good at Internet new media operation to provide technical support and services for the online communication of TCM culture. On the other hand, On the other hand, research and development teams for digital TCM cultural product should also be built up. In view of the wide range and different levels of Internet audiences, when we develop digital TCM cultural products, great importance should not only be attached to their professional and academic qualities, but also to their entertaining, pervasive and inclusive qualities, so as to meet the needs of different audiences and strive to take advantage of the Internet new media technology to enable TCM culture to truly enter the thousands of households in the countries along the Belt and Road.

\section{CONCLUSION}

TCM culture is a treasure of traditional Chinese culture and an important component of China's cultural soft power. Promoting the spread and exchange of TCM culture in countries along the Belt and Road is of great significance to enhance the international influence of China's cultural soft power. At present, the in-depth advancement of the Belt and Road Initiative has brought rare opportunities for the international communication of TCM culture, and we are supposed to firmly seize this opportunity to further speed up the promotion of TCM culture in the countries along the Belt and Road by scientific planning and regulation to make more people in the countries along the Belt and Road feel the infinite charm of TCM culture and the breadth and depth of Traditional Chinese culture, which could finally help to expand the international influence of China's cultural soft power.

\section{REFERENCES}

[1] Yanbin Gao, Huiling Zhao, "Strengthening Research on TCM Culture to Increase its Soft Power", J. World Chinese Medicine, vol.6, pp.461-464, 2011.

DOI:10.3969/j.issn.167 3-7202.2011.06.001

[2] Huiling Zheng, Nana Zhang, Chang'e Zhu, Honglei Zhang, "Research on Evaluation System and Promotion Path of the Cultural Soft Power of Traditional Chinese Medicine", J. Journal of Traditional Chinese Medicine, vol.24, pp.1-5, August 2018. DOI:10.13862/j.cnki.cn431446/r.2018.16.001

[3] Bochao Liu, "Approximately 13,000 International Students Coming to China to Study Traditional Chinese Medicine Every Year". N. Guangming Daily, 2017-0522(06).

[4] Xiaohua Lei, Xiaohua Liu, "China Making New Contributions to the Silk Road of Health", N. Guangxi Daily, 2020-03-26(11).

DOI:10.28292/n.cnki.ngxrb.2020. 002215

[5] White paper on Chinese medicine (full text), N. China News of Traditional Chinese Medicine, 2016-1206, DOI:10.38343/n.cnki.nzyyb.2016.000014

[6] Jiang An, “One Belt and Road Initiative. The development of standardization of Chinese medicine in China", J. Chinese Pharmacy, vol.32, pp.1167-1171, 2018. DOI:10.16153/j.1002-7777.2018.09.002 